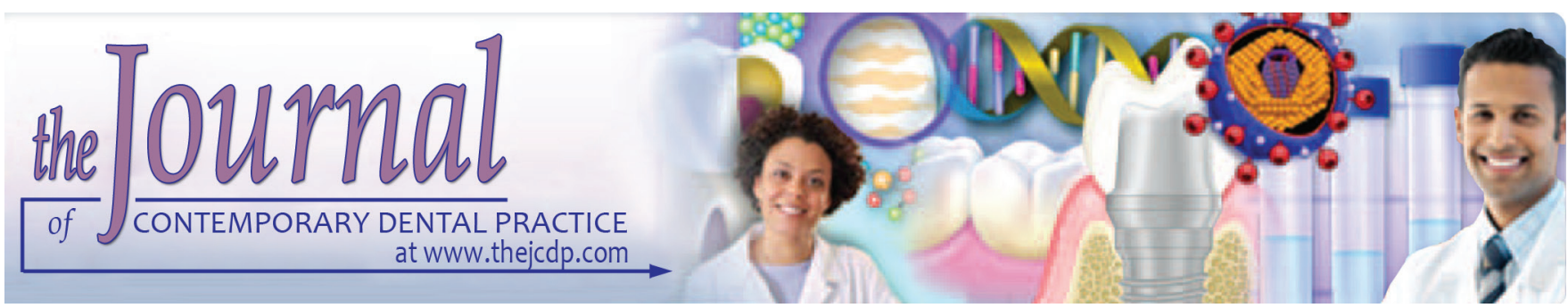

\title{
Effect of Ultrasonic Instrumentation in Treatment of Primary Molars
}

\author{
${ }^{1}$ Rishav Singh, ${ }^{2}$ Pranamee Barua, ${ }^{3}$ Mukesh Kumar, ${ }^{4}$ Romil Safaya, ${ }^{5}$ Hooman Monajemi, ${ }^{6}$ Hootan Monajemi
}

\begin{abstract}
Aim: The aim of this study is to describe the protocol used in the treatment of pulpally necrosed primary molars and to evaluate the effectiveness of ultrasonic instrumentation technique in primary dentition.
\end{abstract}

Materials and methods: A total of 50 primary molars in 40 children, ranging from 8 to 10 years of age, were endodontically treated using standard protocols and ultrasonic instrumentation. The follow-up was done for each case ranging from 1 to $2 \frac{1}{2}$ years.

Results: Clinical and radiographic controls showed a success rate of $97.5 \%$, considering an evaluation time of $19 \pm 9.02$ months.

Conclusion: The use of ultrasonic instrumentation in primary molars with pulpal necrosis succeeded in reducing appointment time and showed a high success rate.

Clinical significance: Ultrasonic instrumentation should be used as a standard protocol in instrumentation of endodontic treatment of primary molars so as to increase the success rate of primary teeth pulpectomies.

Keywords: Children, Endodontics, Primary molar, Radiograph, Ultrasonic.

${ }^{1}$ Department of Pedodontics and Preventive Dentistry Hazaribag College of Dental Sciences \& Hospital, Hazaribagh Jharkhand, India

2Department of Pedodontics and Preventive Dentistry, Regional Dental College, Guwahati, Assam, India

${ }^{3}$ Department of Conservative Dentistry and Endodontics Dr. B.R. Ambedkar Institute of Dental Scinces \& Hospital, Patna Bihar, India

${ }^{4-6}$ Department of Pediatric Dentistry, Sri Dharmasthala Manjunatheshwara College of Dental Sciences, Dharwad Karnataka, India

Corresponding Author: Rishav Singh, Department of Pedodontics and Preventive Dentistry, Hazaribag College of Dental Sciences \& Hospital, Hazaribagh, Jharkhand, India e-mail: rishavsingh@gmail.com
How to cite this article: Singh R, Barua P, Kumar M, Safaya R, Monajemi $\mathrm{H}$, Monajemi $\mathrm{H}$. Effect of Ultrasonic Instrumentation in Treatment of Primary Molars. J Contemp Dent Pract 2017;18(9):750-753.

\section{Source of Support: Nil}

Conflict of Interest: None

\section{INTRODUCTION}

The best space maintainer in both primary and mixed dentition is the primary tooth itself not only because of the clinical crown but also due to the presence of the roots and periodontium that guide the eruption of the succedaneous permanent tooth. In addition, these teeth stimulate maxillary development, enable proper mastication of food, help in phonetics, and prevent deleterious oral habits. Thus, preserving the integrity of deciduous dentition is important for adequate development of permanent dentition. ${ }^{1,2}$

Recognizing the importance of the primary teeth, pediatric dentistry has endeavored to preserve these teeth until they are ready to be replaced or, at least, as close as possible to this time. Thus, primary tooth pulpectomy should be done as a last resort to help keep the pulpally damaged tooth till the normal exfoliation time. ${ }^{3}$

During pulpectomy, the direct and complete intervention of the root canals should be performed, including all the stages of biomechanical canal preparation and filling. Necrotic tissue can only be removed by chemicalmechanical preparation that models the root canal and reduces the number of microbes. ${ }^{4,5}$

Many authors had advocated extirpation of pulpal tissue with instrumentation of the root canals and placement of a resorbable treatment paste. This procedure also required multiple appointments, with three to seven visits needed to complete a pulpectomy procedure. ${ }^{6,7}$ Isolated clinical case reports indicated that the pulpectomy procedure showed excellent results in treating necrotic pulps in primary molars. ${ }^{8,9}$ 
The purpose of the article is to compare primary molars with pulpal necrosis, which were treated with ultrasonic instrumentation during biomechanical canal preparation.

\section{MATERIALS AND METHODS}

The study was approved by the Research Ethics Committee, and the dental charts of 40 children with 50 necrotic primary molars treated with the use of the piezoelectric ultrasound Woodpecker UDS-J (Guilin Woodpecker Medical Instrument Company, China) were analyzed. This type of ultrasonic appliance produces high-frequency vibrations of over $30,000 \mathrm{~Hz}$, which are extremely useful to obtain better cleaning action and smear layer removal inside the canals. The pulpectomy procedure used was divided into two appointments.

An initial periapical radiograph of the tooth to be treated was taken, and the working length of the tooth was determined for the insertion of the files (Fig. 1).

\section{First Endodontic Appointment}

The appointment involves the following steps:

- Infiltrative anesthesia and rubber dam isolation of the operating field;

- Total removal of the carious tissue;

- Chamber opening and location of the root canals; endodontic dressing placement with a sterile cotton pellet-the dressing of choice was $1 / 5$ dilution of formocresol;

- Temporary restoration of the teeth with Cavit G, a hard setting zinc oxide-eugenol cement.

\section{Second Endodontic Appointment}

After removal of the temporary restoration and isolation with rubber dam, biomechanical root canal preparation was next performed in association with an irrigant liquid

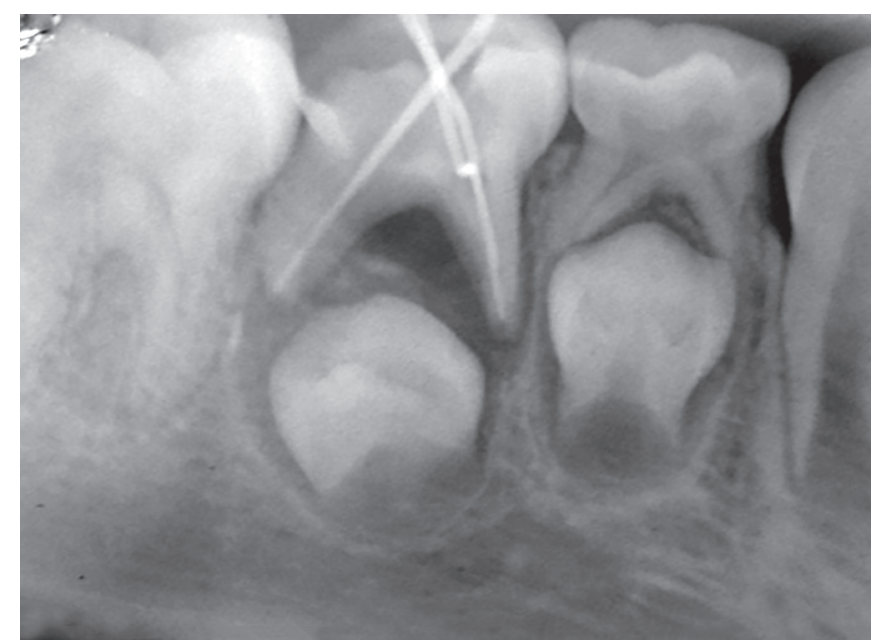

Fig. 1: Preoperative view (sodium hypochlorite 3\%), and K-type files were calibrated to the working length. It was important to explore the canals with a low-caliber conventional file to verify their anatomic details. Next, canal instrumentation began with the patency file and profuse irrigation. Normally, a file caliber 15 was used at this stage. Subsequently, the same file was used with the ultrasonic technique to enlarge the canals rapidly and efficiently. At this stage, the ultrasonic device must be adjusted at the power indicated for endodontics and used under constant irrigation with the agent of choice which, in the treated cases, was sodium hypochlorite. The ultrasonic device must be turned on only when almost entire working length of the file is inside the canal. When the ultrasonic device was turned on, vertical movements were made against all the canal walls, with intervals of 15 seconds, to enlarge and clean it with constant irrigation.

At the end of the ultrasonic instrumentation, the caliber 25 or $30 \mathrm{~K}$-type file was manually used for final canal conformation. Afterward, final irrigation was done with 3\% sodium hypochlorite. With the aid of an ultrasonic appliance, the entire biomechanical root canal preparation process, which takes around 15 minutes, involved:

- Drying the root canals with absorbent paper points of caliber equivalent to the final endodontic file;

- Filling the canals with lentulo spiral, endodontic file, or an association of both. In the present cases of ultrasonic instrumentation, a paste consisting of zinc oxide eugenol was used because it was easy to manipulate and apply and capable of accompanying the physiologic root resorption;

- Vertical compression of the filling material in the pulpal chamber, using a cotton pellet;

- Removing the excessive filling material from the pulpal chamber with cotton pellet imbibed in alcohol;

- Final restoration of the tooth, which was done either with composite resin or resin-modified glass ionomer cement;

- Occlusal adjustment, finishing, and polishing of the restoration;

- Final intraoral periapical radiograph (Fig. 2).

After the endodontic treatment, the tooth was periodically followed up with clinical and radiographic examination.

\section{RESULTS}

A total of 50 cases with pulpal necrosis in primary molars were treated with the described technique in 40 children: 30 boys and 10 girls. Ten children needed to undergo endodontic treatment in two molars each (Table 1). The patients' ages ranged from 6 to 10 years (mean age $=7$ years, 3 months). The success rate was $97.5 \%$ (exact binomial 96\% confidence interval $=74 \%-100 \%$ ) 


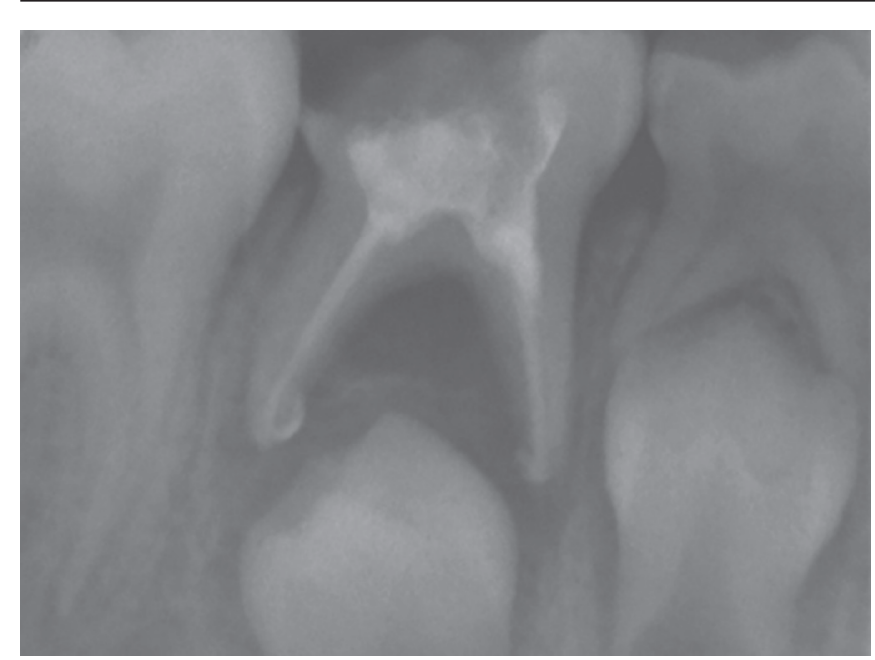

Fig. 2: Postoperative view

Table 1: Study participants details

\begin{tabular}{|c|c|c|c|}
\hline Sex & $\begin{array}{l}\text { Age } \\
\text { (years) }\end{array}$ & $\begin{array}{l}\text { Tooth } \\
\text { number }\end{array}$ & $\begin{array}{l}\text { Follow-up time } \\
\text { (in months) }\end{array}$ \\
\hline Male & 07 & 54 & 15.2 \\
\hline Male & 08 & 55 & 18.4 \\
\hline Male & 06 & 84 & 21 \\
\hline Male & 07.3 & 54 & 23.5 \\
\hline Female & 07.4 & 64.65 & 18.5 \\
\hline Male & 8 & 55 & 17.6 \\
\hline Male & 07.7 & 55 & 16 \\
\hline Female & 07.6 & 84 & 18.9 \\
\hline Male & 06 & 64 & 21.3 \\
\hline Male & 06.5 & 54.75 & 22.2 \\
\hline Female & 7.9 & 65 & 24.5 \\
\hline Male & 08 & 75.74 & 24.1 \\
\hline Male & 06.8 & 84 & 19.3 \\
\hline Male & 07 & 64 & 16 \\
\hline Female & 06 & 54 & 16.3 \\
\hline Male & 06.8 & 85.75 & 16.6 \\
\hline Male & 8.0 & 75 & 15.7 \\
\hline Male & 07 & 84 & 19.8 \\
\hline Male & 07.2 & 65 & 20.2 \\
\hline Female & 08 & 54 & 22.8 \\
\hline Male & 08.1 & 55.65 & 19.8 \\
\hline Male & 07.2 & 74 & 20.7 \\
\hline Male & 08 & 65 & 22.4 \\
\hline Female & 07.3 & 74 & 26.7 \\
\hline Male & 07.2 & 85.75 & 24.2 \\
\hline Male & 6.4 & 54 & 19.3 \\
\hline Male & 7.1 & 64 & 19 \\
\hline Male & 8.4 & 55 & 17.5 \\
\hline Female & 06.7 & 84 & 19.4 \\
\hline Male & 07.3 & 54.55 & 18.9 \\
\hline Male & 07.3 & 64 & 19.5 \\
\hline Female & 08.0 & 75 & 18.5 \\
\hline Male & 08.2 & 84 & 20 \\
\hline Male & 8.4 & 65.74 & 20.5 \\
\hline Female & 07.9 & 55 & 25.2 \\
\hline Male & 8.1 & 74 & 21.3 \\
\hline Male & 06.5 & 64.65 & 23.6 \\
\hline Female & 06.8 & 54 & 19.2 \\
\hline Male & 08.0 & 84.85 & 16.2 \\
\hline Male & 08.0 & 75 & 17.6 \\
\hline
\end{tabular}

with a mean follow-up of 19.9 months. Median was found to be 19.45 for completion of treatment and a range of 11.5 months ( $p<0.001)$. The only case of failure was due to the fracture of a primary molar that had to remain with a temporary restoration. This failure was observed in the 6-month follow-up.

\section{DISCUSSION}

Preservation of an intact primary dentition until eruption of the permanent successors is very important in maintaining the arch form. In the case of a primary tooth that has suffered pulpal insult because of trauma or dental caries, retention of the pulpally involved tooth may preserve the arch space if the normal function can be restored and resolution of the pathologic process can be achieved. In addition to preserving the arch form, utilization of pulpal therapy to maintain the integrity of the primary dentition may:

- Allow for preservation of a pulpally involved primary tooth when the permanent successor is congenitally missing;

- Prevent aberrant tongue habits;

- Prevent possible speech problems;

- Maintain normal masticatory function;

- Preserve esthetics. ${ }^{10-12}$

The use of the ultrasonic instrumentation in the endodontics of primary teeth allows a reduction in the number of clinical appointments. In addition, the referred reduction in attendance time results in decreased physical and emotional stress in pediatric patients and a reduction in costs. ${ }^{13}$

The use of devices that reduce clinical time in pediatric appointments is of great value. It is known that the use of the rotary instrumentation technique in primary molar canals reduced the instrumentation time to onethird in comparison with manual instrumentation. ${ }^{14}$ The disadvantages of rotary instrumentation which consists of nickel-titanium files attached to a low-speed handpiece are the absence of simultaneous irrigation, high cost of the files, limited life span of the files, and need for previous training. Although the ultrasound technique also requires adequate preliminary instruction for use, the advantages of this device are the possibility of adapting conventional files to the insert and constant irrigation, which prevents deposition of dentinal smear layer and necrotic material inside the canals. ${ }^{3}$

The use of the ultrasonic device in permanent teeth is already widely accepted because of its numerous advantages, such as better canal cleaning, constant irrigation, preservation of dental tissue, reduction of postoperative pain, increased bactericidal action, improvement in 
patient's comfort, and shortening of clinical time. ${ }^{15,16}$ Since biomechanical preparation of the primary tooth is similar to the technique used in the permanent tooth, there is no reason not to make use of the advantages offered using ultrasound in the endodontic treatment of children.

In addition to the advantages related to the use of the ultrasound, Pécora et $\mathrm{al}^{17}$ showed that ultrasonic instrumentation enhances dentinal permeability in the pulp chamber floor when compared with manual instrumentation. This is a very important result when considering a primary molar, in which the endodontic lesion is located in the furcation area, since ultrasonic instrumentation allows great diffusion of medications that are applied inside the canals. Primary molars almost always present great difficulties for endodontic treatment because their canal systems are generally atresic, reabsorbed, and altered by the permanent germ. Moreover, primary molars present numerous foramines in the pulpal chamber floor. Due to these characteristics, many dentists choose to extract these teeth. ${ }^{4,5}$

Traditional endodontic techniques with manual instrumentation may lead to a complex treatment of long duration that often makes it impractical to use in pediatric patients who require minimal appointment time. ${ }^{14}$ Considering that the ultrasonic device can make endodontic treatments less time consuming and offer the patient and the operator more comfort, it is of great value in pediatric dentistry. The use of ultrasound technology in endodontics offers the possibility of facilitating access and dilating atresic canals. Adequate dilation assures a high level of root canal asepsis, better conditions for inserting the intracanal medication, and superior penetration and action of chemical agents as a result of the excellent cleaning of the dentinal tubules. ${ }^{3}$

\section{CONCLUSION}

Based on this study's results, the following two conclusions can be made:

1. The use of ultrasonic instrumentation in primary molars with pulpal necrosis enabled the reduction of the children's appointment time and showed a success rate of $97.5 \%$, with a mean follow-up time of 19.9 months.

2. The technique described should be studied further to determine its effectiveness in pediatric dentistry more definitively.

\section{REFERENCES}

1. Brothwell DJ. Guidelines on the use of space maintainers following premature loss of primary teeth. J Can Dent Assoc 1997 Nov;63(10):753, 757-760, 764-766.

2. da Costa CC, Almeida IC, Locks A, da Costa Filho LC. Clinical comparative study of the effects of two types of mandibular space-regaining devices. Gen Dent 2003 Mar-Apr;51(2):120-126.

3. da Costa CC, Kunert GG, da Costa Filho LC, Kunert IR. Endodontics in primary molars using ultrasonic instrumentation. J Dent Child (Chic) 2008 Jan-Apr;75(1):20-23.

4. Clinical Affairs Committee, Pulp Therapy Dentistry Subcommittee. Guideline on pulp therapy for primary and young permanent teeth. Pediatr Dent 2002;24:86-90.

5. Clinical Affairs Committee, Pulp Therapy Dentistry Subcommittee. Guideline on pulp therapy for primary and young permanent teeth. Pediatr Dent 2004;26:115-119.

6. Rabinowitch BZ. Pulp management in primary teeth. Oral Surg Oral Med Oral Pathol 1953 Apr;6(4):542-550.

7. Starkey PE. Methods of preserving primary teeth which have exposed pulps. J Dent Child 1963;30:219-228.

8. Cartwright HV, Bevans JL. Management of two abscessed primary molars in a four-year-old child: report of interesting case. ASDC J Dent Child 1970 May-Jun;37(3):230-232.

9. Starkey PE. Pulpectomy and root canal filling in a primary molar: report of a case. ASDC J Dent Child 1973 May-Jun;40(3):213-217.

10. Goerig AC, Camp JH. Root canal treatment in primary teeth: a review. Pediatr Dent 1983 Mar;5(1):33-37.

11. Camp JH. Pulp therapy for primary and young permanent teeth. Dent Clin North Am 1984 Oct;28(4):651-668.

12. Hicks MJ, Barr ES, Flaitz CM. Formocresol pulpotomies in primary molars: a radiographic study in a pediatric dentistry practice. J Pedod 1986 Summer;10(4):331-339.

13. Costa, CC. O Uso do Ultra-Som em Odontopediatria. In: Mesquita E, Kunert IR, editors. O Ultra-som na Prática Odontologica. Sao Paulo: Artmed; 2006. p. 216-235.

14. Silva LA, Leonardo MR, Nelson-Filho P, Tanomaru JM. Comparison of rotary and manual instrumentation techniques on cleaning capacity and instrumentation time in deciduous molars. J Dent Child (Chic) 2004 Jan-Apr;71(1):45-47.

15. Goldberg F, Araujo JA. Estudio comparativo de la limpieza obtenida com el uso de la instrumentacion manual y de la instrumentacion con aparatologia automatic en conductos mesiales de molares inferiores. Rev Asoc Odontol Argent 1993;81(4):258-261.

16. Lea SC, Walmsley AD. Technology, ultrasonics and dentistry. Dent Update 2002 Oct;29(8):390-395.

17. Pécora JD, Costa WF, Maia Campos G. A study of the dentinal permeability of the pulp chamber floor of human lower molars with separate roots. Braz Dent J 1990 Feb;1(1):17-24. 